BULLETIN OF THE

AMERICAN MATHEMATICAL SOCIETY

Volume 80, Number 4, July 1974

\title{
THE NOVEMBER MEETING IN TUCSON
}

The seven hundred tenth meeting of the American Mathematical Society was held at the University of Arizona, Tucson, Arizona, on Friday and Saturday, November 23 and 24, 1973. There were 53 registrants including 44 members of the Society.

By invitation of the Committee to Select Hour Speakers for Far Western Sectional Meetings, there were two hour addresses. Professor Andrew P. Ogg of the University of California, Berkeley, lectured on Diophantine equations andmodular forms. He was introduced by Professor Clark Benson. Professor Robert R. Phelps of the University of Washington spoke on The Choquet representation in the complex case; he was introduced by Professor Victor L. Klee, Jr.

There were three sessions of ten-minute contributed papers, chaired by Professors Robert Bekes, Robert E. O'Malley, Jr., and Alexander P. Stone. There were also two special sessions on Singular Perturbations. These sessions were organized by Professors Paul C. Fife and Wilfred M. Greenlee. Thirty-minute talks were given by Professors Donald S. Cohen, Julian D. Cole, Frank C. Hoppensteadt, Joseph B. Keller, J. Kevorkian, Norman R. Lebovitz, and Robert E. O'Malley, Jr.

Local arrangements were handled by Professor Larry C. Grove.

EUGENE, OREGON

KenNeth A. Ross Associate Secretary 